\title{
Ionophores and Cytochalasins Modulate Branching in Achlya bisexualis
}

\author{
By RUTH L. HAROLD ${ }^{1 *}$ AND FRANKLIN M. HAROLD 1,2 \\ ${ }^{1}$ Department of Molecular and Cellular Biology, National Jewish Center for Immunology and \\ Respiratory Medicine, Denver, CO 80206, USA \\ ${ }^{2}$ Department of Biochemistry, Biophysics and Genetics, University of Colorado Health Sciences \\ Center, Denver, CO 80262, USA
}

(Received 8 May 1985; revised 21 June 1985)

\begin{abstract}
Hyphae of Achlya bisexualis growing on a medium deficient in amino acids elongated but produced relatively few branches. Branching was enhanced by three classes of compound: cytochalasins A and E, the calcium ionophores A23187 and ionomycin and proton ionophores such as tetrachlorosalicylanilide (TCS), carbonylcyanide $m$-chlorophenylhydrazone (CCCP), and carbonylcyanide $p$-trifluoromethoxyphenylhydrazone (FCCP). We suggest that the effects of cytochalasins reflect the disruption of a microfilament-based system for vesicle transport. Enhancement of branching by ionophores implicates cytoplasmic ions in the control of branch initiation. There may be links between these phenomena and the earlier discovery that a new point of proton entry precedes the emergence of a branch and predicts its locus.
\end{abstract}

\section{INTRODUCTION}

Fungal hyphae grow in two modes, linear extension and branching. The principles of hyphal extension are relatively well understood. Turgor pressure supplies the driving force for surface expansion, and precursors for the synthesis of new cell wall and plasma membrane are assembled in the Golgi apparatus or its equivalent, packaged in vesicles and transported to the hyphal apex under the influence of a polarizing mechanism. Growth is thus confined to the extreme tip, where vesicle fusion and exocytosis of their contents take place (Grove, 1978; Trinci, 1978; Gooday, 1983). By contrast, the branching process is still incompletely understood. Initiation of a branch must involve selection of a locus, diversion of precursor vesicles to the new site, controlled hydrolysis of the existent wall, and ultimately the construction of a new pathway of vesicle transport. A variety of localized disturbances could initiate a branch including an excessive supply of vesicles, disruption of vesicle fusion at the original apex or the disorganization of vesicle transport (Mullins, 1973; Nolan \& Bal, 1974; Trinci, 1979). Very little is known about these processes in fungi, or about the signals that regulate them.

However, a novel clue came from recent research on transcellular ion currents. The water mould Achlya bisexualis, in common with other mycelial fungi, generates endogenous electric currents such that positive charges enter the apical zone of growing hyphae and exit distally (Kropf et al., 1983, 1984; Gow, 1984). In Achlya the current is carried by protons and apparently arises by the segregation of proton-linked porters from proton pumps, the porters being preferentially localized in the apical zone (Kropf et al., 1984; Gow et al., 1984; D. L. Kropf, unpublished results). Branches always arise in a zone of inward current, and a new point of current entry often precedes the emergence of a branch and predicts its locus (Kropf et al., 1983). This apparent connection between proton influx and branching prompted us to examine the effects of proton-conducting ionophores on branching in Achlya. We report here a survey of the effects of a variety of ionophores, cytochalasins and other inhibitors.

\footnotetext{
Abbreviations: TCS, tetrachlorosalicylanilide; CCCP, carbonylcyanide $m$-chlorophenylhydrazone; FCCP, carbonylcyanide $p$-trifluoromethoxyphenylhydrazone; DCCD, $N, N^{\prime}$-dicyclohexylcarbodiimide; TMB-8, 8(diethylamino)octyl-3,4,5-trimethoxybenzoate hydrochloride; DES, diethylstilboestrol.
} 


\section{METHODS}

Organism and media. Achlya bisexualis, female strain T5, was obtained from the American Type Culture Collection. Mycelia were maintained on PYG agar (Bacto-peptone, $1.25 \mathrm{~g}^{-1}$; yeast extract, $1.25 \mathrm{~g} \mathrm{l}^{-1}$; glucose, $3 \mathrm{~g} \mathrm{1}^{-1}$; Bacto-agar, $20 \mathrm{~g}^{-1}$ ). Zoospores for use as inocula were produced as described by Gow et al. (1984). The sporulation medium contained $0.25 \mathrm{mM}-\mathrm{CaCl}_{2}, 0.25 \mathrm{mM}-\mathrm{KCl}$ and $1.0 \mathrm{mM}-\mathrm{K}-\mathrm{PIPES}, \mathrm{pH} 6.5$.

All experiments were done in $\mathrm{DMA}_{100}$, an amino acid deficient, defined medium which contained the same concentrations of inorganic salts, trace metals, buffer and glucose as the DMA of Kropf et al. (1984), but in which the concentration of amino acids was reduced one hundred fold. Its composition was thus: K-PIPES, $1.0 \mathrm{mM}$; $\mathrm{KH}_{2} \mathrm{PO}_{4}$ and $\mathrm{K}_{2} \mathrm{HPO}_{4}, 0.75 \mathrm{mM}$ each; $\mathrm{MgCl}_{2}, 1.0 \mathrm{mM} ; \mathrm{CaCl}_{2}, 0.5 \mathrm{mM}$; trace metals; glucose, $10 \mathrm{~mm}$; glutamic acid, $13.6 \mu \mathrm{M}$; methionine, $2 \cdot 2 \mu \mathrm{M}$; isoleucine, leucine, threonine, valine and lysine, $2.0 \mu \mathrm{M}$ each; glycine, arginine, phenylalanine, tyrosine and serine, $1.0 \mu \mathrm{M}$; histidine $0.5 \mu \mathrm{M}$ and tryptophan, $0.2 \mu \mathrm{M}$. The $\mathrm{pH}$ was adjusted to 6.5 with $\mathrm{HCl}$. Solidified media also contained 1 or $2 \%(\mathrm{w} / \mathrm{v})$ Difco Noble agar, as specified below.

Achlya hyphae elongated at a rate of 3-5 $\mu \mathrm{m} \mathrm{min}^{-1}$ in both DMA and DMA ${ }_{100}$, but the diameter of the hyphae in $\mathrm{DMA}_{100}$ was only $15-20 \mu \mathrm{m}$, compared with $30 \mu \mathrm{m}$ in DMA. Because of the amino acid deficiency, the frequency of branching in $\mathrm{DMA}_{100}$ was greatly reduced (Thomas \& Mullins, 1969; Barksdale, 1970).

Testing ionophores and other inhibitors. Two methods were used.

(1) Diffusion gradients in agar plates. A 2-5 $\mu$ l volume of spore suspension containing $20-40$ zoospores was spotted onto each of the four quadrants of a $100 \mathrm{~mm}_{\mathrm{i}}$ agar plate $\left(15 \mathrm{ml} \mathrm{DMA} \mathrm{A}_{100}, 1 \%\right.$, w/v, agar $)$; spots were placed $17 \mathrm{~mm}$ from the centre. The plates were incubated at $24^{\circ} \mathrm{C}$, producing radial colonies. After $22 \mathrm{~h}$ a plug of agar, $13 \mathrm{~mm}$ in diameter, was removed from the centre of the dish with a corkborer, and replaced with the same volume of molten agar $\left(53^{\circ} \mathrm{C}\right)$ containing the compound to be tested. Diffusion of inhibitor from the plug gave rise to a gradient of inhibitor concentration. Results were scored after $20 \mathrm{~h}$.

(2) Uniform fields in liquid media. Spore suspensions containing 20-40 zoospores were inoculated onto the surface of a very thin layer of agar $\left(11 \mathrm{ml} \mathrm{DMA} A_{100}, 2 \%, \mathrm{w} / \mathrm{v}\right.$, agar). The plates were incubated at $24^{\circ} \mathrm{C}$, producing radial colonies. To examine the response to a compound a $12 \mathrm{~mm}$ plug of agar bearing a colony 18 -h-old was glued into a $60 \mathrm{~mm}$ tissue culture dish (Silastic Elastomer; Dow Corning), and flooded with growth medium; after the hyphae had equilibrated for $1 \mathrm{~h}$, inhibitor was added. Results were scored 3-5 h later.

The degree of branching was estimated visually by comparison with control plates run in parallel with the experimental ones. Experimental and control plates were run in duplicate and each compound was tried at least twice. Attempts to put the scoring on a quantitative basis were not successful: individual hyphae vary considerably, in part because they grow both within the agar and on its surface and are therefore not equally exposed to the reagents.

Microscopy and photography were done with a Zeiss IM35 inverted microscope.

Stock solutions. These were prepared as follows.

(1) TMB-8, dibutyryl cAMP and $\mathrm{HCl}$ were dissolved directly in growth medium just before use.

(2) Nocodazole, carbendazim, suloctidyl and griseofulvin were dissolved in DMSO. Concentrations of stock solutions were such that the final concentration of DMSO present in the central agar plug (method 1) did not exceed $2 \%(\mathrm{v} / \mathrm{v})$. Agar plugs containing $2 \%$ DMSO alone had no effect on growth or branching in nearby colonies. Only nocodazole was tested in liquid medium as well as solid medium. Volumes of a $10 \mathrm{~mm}$ stock solution in DMSO were diluted into growth medium such that the final concentration of DMSO did not exceed $0 \cdot 2 \%(\mathrm{v} / \mathrm{v})$. This concentration did not affect growth or branching.

(3) All other reagents were dissolved in ethanol. The concentrations of stock solutions were such that the ethanol concentrations did not exceed $2 \%(\mathrm{v} / \mathrm{v})$ and $0.2 \%(\mathrm{v} / \mathrm{v})$ in methods 1 and 2 respectively. Ethanol at these concentrations had no effect on growth or branching.

Reagents. Ionophores and inhibitors were purchased from Sigma or from Aldrich. TMB-8 was purchased from Calbiochem. We acknowledge with thanks gifts of the following reagents: ionomycin (C.-M. Liu, Hoffman-La Roche, Nutley, NJ, USA); carbendazim (H. C. Van der Plas, Landbouwhogeschool, Wageningen, The Netherlands); thiabendazole (L. R. Mandel, Merck Sharpe and Dohme Research Laboratories, Rahway, NJ, USA); FCCP (P. G. Heytler, E. I. DuPont de Nemours, Wilmington, Del., USA); suloctidil (G. Lambelin, Continental Pharmacy, Belgium); nupercaine $\mathrm{HCl}$ (CIBA, Summit, NJ, USA).

\section{RESULTS}

Table 1 lists all the compounds surveyed and indicates their effect on branching. Fig. 1 $(a)$ shows the edge of a radial colony growing on $\mathrm{DMA}_{100}$ agar; Fig. $1(b)$ shows intense apical branching induced by a diffusion gradient of the proton-conducting uncoupler TCS. Stimulation of branching by TCS was first noted some $5 \mathrm{~h}$ after addition of the reagent. Individual hyphae varied in their tolerance to TCS. After $7 \mathrm{~h}$ some hyphae were necrotic while others continued to elongate at $1-2 \mu \mathrm{m} \mathrm{min}^{-1}$ and to branch. However, by $20 \mathrm{~h}$ most of the hyphae and branches 
Table 1. Compounds that enhance branching in A. bisexualis

Inhibitors were applied either by diffusion through solid medium (agar plates) or by addition to liquid medium. The score is a visual estimate of the extent of branching: + , detectable enhancement of branching; ++ , moderate branching (Fig. 1c); +++ , profuse branching (Figs $1 b, 2 b$ and $2 c$ ); 0 , no effect.

\begin{tabular}{|c|c|c|c|c|c|}
\hline \multirow[b]{2}{*}{ Compounds } & \multicolumn{2}{|c|}{ Agar plates* } & \multicolumn{3}{|c|}{ Liquid medium $\dagger$} \\
\hline & Concn $(\mathrm{mm}) \ddagger$ & Score & Concn $(\mu \mathrm{M}) \S$ & & Score \\
\hline \multicolumn{6}{|l|}{ Ionophores } \\
\hline TCS & $0 \cdot 1$ & $+t+$ & $0 \cdot 2-0 \cdot 5$ & & 0 \\
\hline $\mathrm{CCCP}$ & $0 \cdot 2$ & +++ & & ND & \\
\hline FCCP & 0.2 & +++ & & ND & \\
\hline DNP & 1 & ++ & $20-100$ & & 0 \\
\hline Nigericin & 1 & + & $1-5$ & & 0 \\
\hline A23187 & 0.05 & 0 & 10 & & $++t$ \\
\hline Ionomycin & 0.05 & + & 20 & & ++ \\
\hline \multicolumn{6}{|l|}{ Cytochalasins } \\
\hline A & $0 \cdot 2$ & $++t$ & 6 & & +++ \\
\hline B & $0 \cdot 2$ & 0 & 100 & & 0 \\
\hline D & $0 \cdot 2$ & 0 & 100 & & 0 \\
\hline $\mathrm{E}$ & & & 100 & & ++ \\
\hline \multicolumn{6}{|l|}{ Miscellaneous } \\
\hline Amino acids $\|$ & & & 3200 & & $++t$ \\
\hline $\mathrm{HCl}$ & 50 & ++ & & ND & \\
\hline DES & 1 & $+t$ & $1-10$ & & 0 \\
\hline DCCD & $0 \cdot 5$ & + & & ND & \\
\hline
\end{tabular}

ND, Not done.

* The following compounds did not enhance branching on agar plates: antimycin A ( 1 and $10 \mathrm{~mm}$ in the plug), rotenone $(1 \mathrm{mM})$, HOQNO $(100 \mu \mathrm{M})$, peliomycin $\left(70 \mu \mathrm{g} \mathrm{ml}^{-1}\right)$, nocadazole $(100 \mu \mathrm{M})$, carbendazim $(100 \mu \mathrm{M})$, thiabendazole $(500 \mu \mathrm{M})$, colchicine $(1 \mathrm{mM})$, griseofulvin $(100 \mu \mathrm{M})$ and dibutyryl cAMP $(10 \mathrm{mM})$. The following compounds inhibited growth and also prevented the normal amount of branching: cycloheximide $\left(100 \mu \mathrm{g} \mathrm{ml}^{-1}\right)$, actinomycin $\mathrm{D}\left(50 \mu \mathrm{g} \mathrm{ml}^{-1}\right)$, suloctidyl $(1 \mathrm{mM})$ and oligomycin $(500 \mu \mathrm{M})$.

$\dagger$ The following compounds did not enhance branching in liquid medium: nocadazole $(20 \mu \mathrm{M})$, trifluoperazine $(20 \mu \mathrm{M})$, chlorpromazine $(30 \mu \mathrm{M})$, haloperidol $(100 \mu \mathrm{M})$, procaine $(5 \mathrm{mM})$, nupercaine $(0 \cdot 2 \mathrm{mM})$, tetracaine $(0 \cdot 5 \mathrm{mM})$. 4- $\beta$-phorbol 12- $\beta$-myristate 13- $\alpha$-acetate $\left(0.5 \mu \mathrm{g} \mathrm{ml}^{-1}\right)$. TMB-8 $(200 \mu \mathrm{M})$ inhibited both growth and amino acid induced branching.

$\ddagger$ Concentration of compound in the central plug.

$\S$ Concentration of compound in the liquid medium.

\| Mixture of 14 amino acids (see Methods).

facing the plug had developed large vacuoles and had stopped growing. Similar observations were made with all the proton-conducting ionophores listed in Table 1. Diethylstilbestrol (DES) was also a good inducer of branching; DCCD and nigericin were much less potent (not illustrated). The effects of cytochalasins (Fig. 1c) are discussed below.

TCS and other proton-conducting ionophores enhanced branching on solid media, but we could not reproduce this effect in liquid media. It seems unlikely that branching is related to the inhibitor gradient generated by the plug. We suspect that the diffusion technique presents extending hyphae with a concentration of inhibitor that stimulates branching but does not kill the cell.

The calcium ionophores A23187 and ionomycin induced branching only in liquid medium: Fig. 2(a) shows a control in $0 \cdot 2 \%$ ethanol; Fig. $2(b)$ shows the effect of A23187. Branching enhancement by these compounds could not be demonstrated on solid medium, possibly because they are extremely insoluble in water. The frequency and pattern of branching induced by A23187 were the same in medium modified to contain only $5 \mu \mathrm{M}$ added $\mathrm{Ca}^{2+}$, plus $100 \mu \mathrm{M}-$ EGTA (DMA ${ }_{100}$ contains $0.5 \mathrm{mM}$ free $\mathrm{Ca}^{2+}$ ions, the modified medium contains about $50 \mathrm{nM}$; Caldwell, 1970). This observation suggests that ionophore-induced branching does not depend on extracellular calcium ions. Higher concentrations of EGTA along with A23187 prevented hyphal extension. 

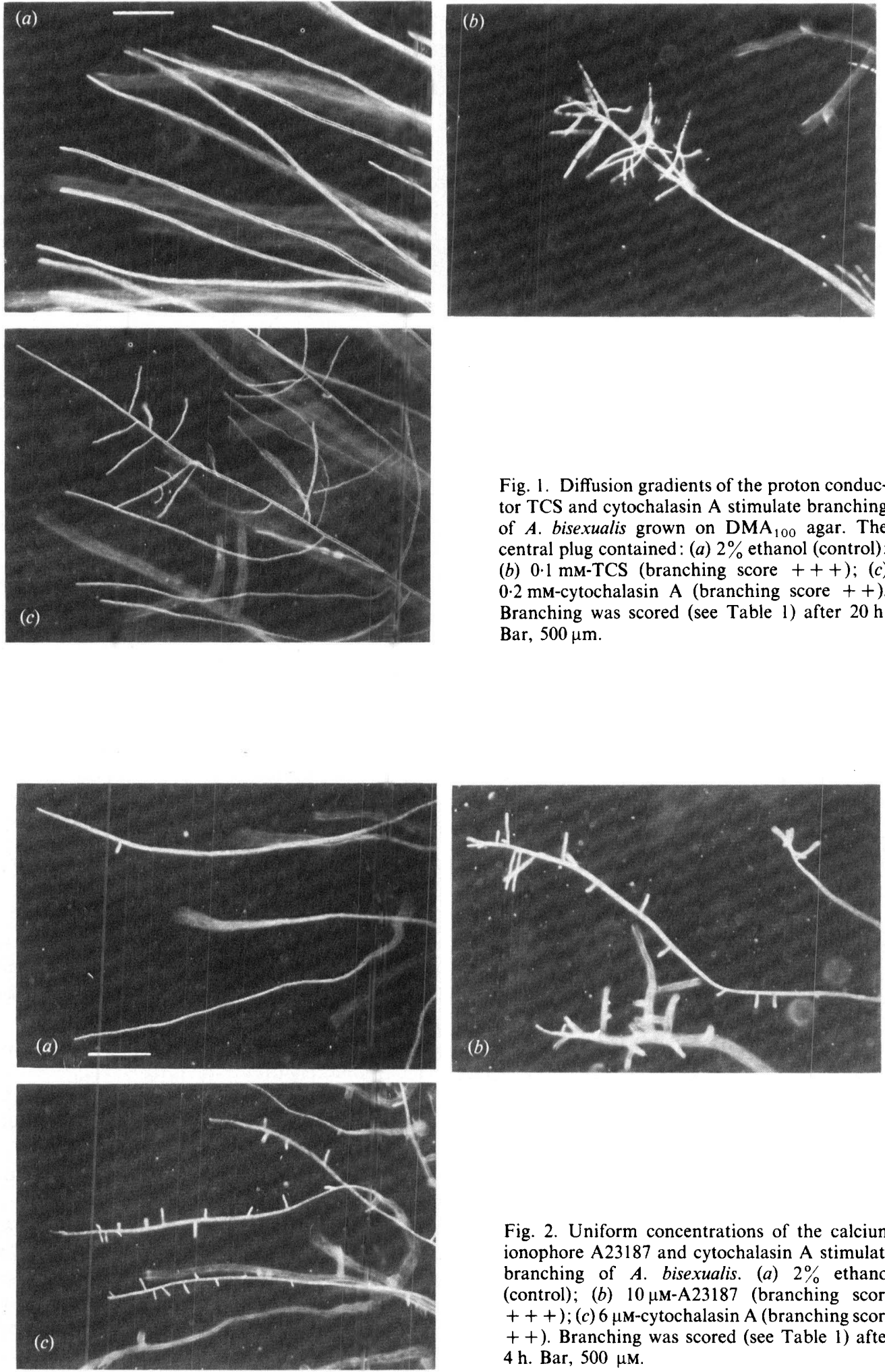

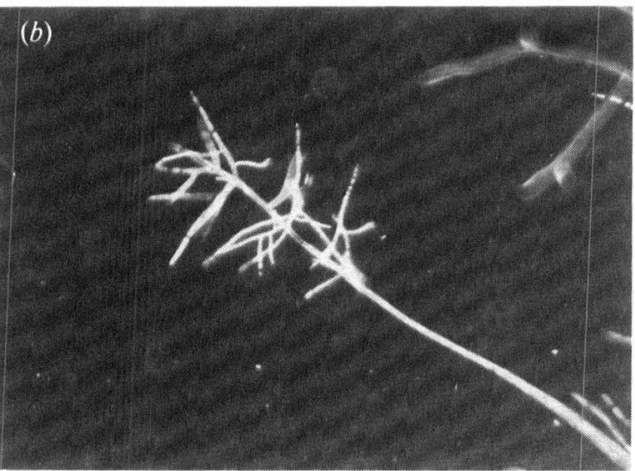

Fig. 1. Diffusion gradients of the proton conductor TCS and cytochalasin A stimulate branching of $A$. bisexualis grown on $\mathrm{DMA}_{100}$ agar. The central plug contained: (a) $2 \%$ ethanol (control); (b) $0.1 \mathrm{~mm}$-TCS (branching score +++ ); (c) 0.2 mM-cytochalasin A (branching score ++ ). Branching was scored (see Table 1) after $20 \mathrm{~h}$. Bar, $500 \mu \mathrm{m}$.
Fig. 2. Uniform concentrations of the calcium ionophore A23187 and cytochalasin A stimulate branching of $A$. bisexualis. (a) $2 \%$ ethanol (control); (b) $10 \mu \mathrm{M}-\mathrm{A} 23187$ (branching score +++ ); (c) $6 \mu \mathrm{M}$-cytochalasin A (branching score ++ ). Branching was scored (see Table 1) after 4 h. Bar, $500 \mu \mathrm{M}$. 
Cytochalasin A reproducibly enhanced branching on solid medium and sometimes enhanced branching in liquid medium also (Figs $1 c$ and $2 c$ ). Cytochalasin $\mathrm{E}$ also induced branching, though less well; cytochalasins $B$ and D had no effect on either growth or branching. None of the inhibitors of microtubule assembly enhanced branching.

Hyphae growing in liquid $\mathrm{DMA}_{100}$ extended at the normal rate but produced few branches which always emerged at least $150 \mu \mathrm{m}$ behind the old tip. Addition of amino acids at the concentration used in DMA induced marked apical and lateral branching within $1-2 \mathrm{~h}$ (not illustrated). The inhibitor TMB-8 at a concentration $(200 \mu \mathrm{m})$ that slowed apical extension to half its normal rate, overrode this amino acid stimulation. Various calmodulin antagonists, local anaesthetics and phorbol esters neither stimulated branching nor inhibited it (Table 1, footnote).

\section{DISCUSSION}

Three classes of compounds enhanced branching of Achlya bisexualis growing on an amino acid deficient, defined medium: cytochalasins A and E; the calcium-ionophores A23187 and ionomycin; and the proton-ionophores TCS, CCCP, FCCP and DNP. Branching was also enhanced by DES, a putative inhibitor of the proton-transport ATPase of the plasma membrane, but was either unaffected or suppressed by other inhibitors of metabolism (Table 1). Calcium ionophores and proton ionophores elicited many apical branches as well as lateral ones; cytochalasins induced chiefly lateral branches (Figs 1 and 2). Such pharmacological observations must be interpreted with caution; nevertheless we believe that the results hold valid clues to the signals that control hyphal branching.

Low concentrations of cytochalasins have been reported to induce branching in a number of fungi, usually with concurrent inhibition of the growth of the original tip (Betina et al., 1972; Thomas, 1978; Allen et al., 1980; Grove \& Sweigard, 1980). They also have drastic effects on the growth, morphology and locomotion of many animal cells in culture (Wessels et al., 1971), in which it is now generally agreed that they exert their effects by blocking the elongation of actin filaments or by disrupting microfilament networks (Bray, 1979; Lin et al., 1980; Brown \& Spudich, 1981; Yahara et al., 1982; Schliwa, 1982). Microfilaments and actin have been reported in several fungi (Howard, 1981; Sikora \& Marzluf, 1982; Hoch \& Staples, 1983), including Achlya (Silver et al., 1983). In Achlya bisexualis cytochalasins A and E are the active species; although cytochalasin A exerts several inhibitory effects on Achlya ambisexualis (Thomas et al., 1974; Manavathu \& Thomas, 1976, 1983), it seems likely that branching reflects the disruption of microfilaments. Actin has been implicated in the polarization of growth and in the localized deposition of new cell wall in Saccharomyces (Kilmartin \& Adams, 1984; Adams \& Pringle, 1984; Novick \& Botstein, 1985), and the evidence strongly suggests that the transport of precursor vesicles is mediated by actin filaments. If a similar pathway exists in Achlya, its disruption may well divert vesicles to sites other than the apex and thus initiate a lateral branch (Trinci, 1979).

The calcium ionophores A23187 and ionomycin elicit a variety of biological responses, probably by raising the concentration of free calcium ion in the cytosol (Cheung, 1980). Examples include the induction of budding in moss (Saunders \& Hepler, 1982) and of branching in Neurospora (Reissig \& Kinney, 1983). A23187 elicited branching in Achlya even when the external calcium level was reduced to $50 \mathrm{nM}$, and both in the presence and absence of $\mathrm{Mg}^{2+}$ ions; this suggests that branching occurs in response to the release of calcium ions from an intracellular reservoir. Reissig \& Kinney (1983) noted that removal of the ionophore after 30 min did not prevent subsequent branching, and inferred that a transient rise in the calcium concentration is sufficient to trigger branching. In our hands, complete removal of A23187 required repeated washings which induced significant branching in control cultures. We therefore regard it as premature to attribute branching to a transient calcium signal; indeed, any rise in cytosolic calcium has yet to be demonstrated directly. We also have no information concerning the process that is disrupted by calcium ions; cytoskeletal filaments are among the possible sites. 
If normal branching occurs in response to a rise in the cytosolic calcium concentration, inhibitors of calcium release might be expected to suppress branching. The compound TMB-8 is said to have this effect (Malagodi \& Chiou, 1974; Europe-Finner \& Newell, 1984); it did prevent the intense branching normally observed when amino acids were added to hyphae elongating in DMA $_{100}$. TMB-8 has recently been shown to inhibit oxidative phosphorylation (Brand \& Felber, 1984) and should not be used uncritically. Nevertheless, the role of calcium ions in the control of branching clearly deserves closer scrutiny.

To our knowledge, proton-ionophores have not been reported earlier to induce branching in fungi, though they elicit chemotropic growth of Blastocladiella rhizoids (Harold \& Harold, 1980) and stimulate the germination of Neurospora conidia (Turian \& Michea-Hamzehpour, 1983). The sequence of events that leads to branching in Achlya is unknown. We think it unlikely that uncoupling of oxidative phosphorylation is the primary effect, since neither oligomycin nor inhibitors of respiration elicited branching (Table 1, footnote). Proton-ionophores would be expected to release calcium ions from mitochondria, with a consequent rise in the cytosolic calcium concentration. Reduction of the cytosolic $\mathrm{pH}$ is another way by which protonionophores may elicit their effects. DES, a putative inhibitor of the proton-translocating ATPase of fungal plasma membranes (Goffeau \& Slayman, 1981; D. L. Kropf, unpublished results), may also stimulate branching by acidifying the cytoplasm. The study of transcellular proton currents led us earlier to suggest a possible link between localized acidification of the cytoplasm and branch emergence (Kropf et al., 1983, 1984). Whether such a link actually exists must now be explored with the aid of methods that can monitor the local $\mathrm{pH}$ in particular regions of the cytoplasm.

We acknowledge with thanks much helpful advice from Drs Neil Gow, Arthur Koch and Darryl Kropf. This research was supported in part by Public Health Service grant AI-03568 from the National Institute of Allergy and Infectious Diseases, and National Science Foundation grant PCM 800439 from the Metabolic Biology Program.

\section{REFERENCES}

Adams, A. E. M. \& Pringle, J. R. (1984). Relationship of actin and tubulin distribution to bud growth in wild-type and morphogenetic-mutant Saccharomyces cerevisiae. Journal of Cell Biology 98, 934-945.

Allen, E. D., Aiuto, R. \& Sussman, A. S. (1980). Effects of cytochalasins on Neurospora crassa. I. Growth and ultrastructure. Protoplasma 102, 63-75.

BarksDale, A. W. (1970). Nutrition and antheridiolinduced branching in Achlya ambisexualis. Mycologia 62, 411-420.

BetinA, V., Mičeková, D. \& Nemec, P. (1972). Antimicrobial properties of cytochalasins and their alteration of fungal morphology. Journal of General Microbiology 71, 343-349.

Brand, M. \& Felber, S. (1984). The intracellular calcium antagonist TMB-8 [8- $N, N^{\prime}$-(diethylamino)octyl-3,4,5-trimethoxybenzoate] inhibits mitochondrial ATP production in rat thymocytes. Biochemical Journal 224, 1027-1030.

BraY, D. (1979). Cytochalasin action. Nature, London 282, 671 .

Brown, S. S. \& SPUdich, J. A. (1981). Mechanism of action of cytochalasin: evidence that it binds to actin filament ends. Journal of Cell Biology 88, 487-491.

Caldwell, P. C. (1970). Calcium chelation and buffers. In Calcium and Cellular Function, pp. 10-16. Edited by A. W. Cuthbert. New York: St Martin's Press.

Cheung, W. Y. (1980). Calmodulin plays a pivotal role in cellular regulation. Science 207, 19-27.

Europe-Finner, G. N. \& Newell, P. C. (1984). Inhibition of cyclic GMP formation and aggregation in Dictyostelium by the intracellular $\mathrm{Ca}^{2+}$ antagonist TMB-8. FEBS Letters 171, 315-319.

Goffeau, A. \& Slayman, C. W. (1981). The protontranslocating ATPase of the fungal plasma membrane. Biochimica et biophysica acta 639, 197-223.

Gooday, G. W. (1983). The hyphal tip. In Fungal Differentiation, pp. 315-356. Edited by J. E. Smith, New York: Marcel Dekker.

Gow, N. A. R. (1984). Transhyphal electrical currents in fungi. Journal of General Microbiology 130, 33133318.

Gow, N. A. R., KROPF, D. L. \& HaRold, F. M. (1984). Growing hyphae of Achlya bisexualis generate a longitudinal $\mathrm{pH}$ gradient in the surrounding medium. Journal of General Microbiology 130, 2967-2974.

Grove, S. N. (1978). The cytology of hyphal tip growth. In The Filamentous Fungi, vol. III, pp. 28-50. Edited by J. E. Smith \& D. R. Berry. New York: John Wiley.

Grove, S. N. \& Sweigard, J. A. (1980). Cytochalasin A inhibits spore germination and hyphal tip growth in Gilbertella persicaria. Experimental Mycology 4, 239-250.

HaROLD, R. L. \& HaRold, F. M. (1980). Oriented growth of Blastocladiella emersonii in gradients of ionophores and inhibitors. Journal of Bacteriology 144, 1159-1167.

Hoch, H. C. \& STAPLeS, R. C. (1983). Visualization of actin in situ by rhodamine-conjugated phalloin in the fungus Uromyces phaseoli. European Journal of Cell Biology 32, 52-58.

HowARD, R. (1981). Ultrastructural analysis of hyphal 
tip cell growth in fungi: spitzenkörper, cytoskeleton and endomembranes after freeze-substitution. Journal of Cell Sciences 48, 89-103.

Kilmartin, J. V. \& Adams, A. E. M. (1984). Structural rearrangements of tubulin and actin during the cell cycle of the yeast Saccharomyces. Journal of Cell Biology 98, 922-933.

Kropf, D. L., Lupa, M. D. A., Caldwell, J. H. \& Harold, F. M. (1983). Cell polarity: endogenous ion currents precede and predict branching in the water mould Achlya. Science 220, 1385-1387.

Kropf, D. L., Caldwell, J. H:, Gow, N. A. R. \& HAROLD, F. M. (1984). Transcellular ion currents in the water mould Achlya. Amino acid proton symport as a mechanism of current entry. Journal of Cell Biology 99, 486-496.

LiN, D. C., Tobin, K. D., Grumet, M. \& Lin, S. (1980). Cytochalasins inhibit nuclei-induced actin polymerization by blocking filament elongation. Journal of Cell Biology 84, 455-460.

Malagod, M. H. \& Chiou, C. Y. (1974). Pharmacological evaluation of a new $\mathrm{Ca}^{2+}$ antagonist TMB-8: studies in smooth muscles. European Journal of Pharmacology 27, 25-33.

Manavathu, E. K. \& Thomas, D. D. S. (1976). A nonpenetrating thiol reagent mimics cytochalasin A inhibition of secretory protein synthesis. Biochemical and Biophysical Research Communications 71, 280285.

Manavathu, E. K. \& Thomas, D. D. S. (1983). Cytochalasin $\mathrm{A}$ and respiratory inhibition in the water mould Achlya ambisexualis. Canadian Journal of Microbiology 29, 15-20.

Mullins, J. T. (1973). Lateral branch formation and cellulase production in the water moulds. Mycologia 65, 1007-1014.

Nolan, R. A. \& BaL, A. K. (1974). Cellulase localization in hyphae of Achlya ambisexualis. Journal of Bacteriology 117, 840-843.

Novick, P. \& Botstein, D. (1985). Phenotypic analysis of temperature-sensitive yeast actin mutants. Cell $\mathbf{4 0}$, 405-416.

ReissiG, J. L. \& KinNey, S. G. (1983). Calcium as a branching signal in Neurospora crassa. Journal of Bacteriology 154, 1397-1402.

Saunders, M. J. \& HePler, P. K. (1982). Calcium ionophore A23187 stimulates cytokinin-like mitosis in Funaria. Science 217, 943-945.
SCHLIWA, M. (1982). Action of cytochalasin D on cytoskeletal networks. Journal of Cell Biology 92, 7991.

Sikora, L. \& Marzluf, G. A. (1982). Identification and isolation of actin from Neurospora crassa. Journal of General Microbiology 128, 439-445.

Silver, J. C., Andrews, D. R. \& Pekkala, D. (1983). Effect of heat shock on synthesis and phosphorylation of nuclear and cytoplasmic proteins in the fungus Achlya. Canadian Journal of Biochemistry and Cell Biology 61, 447-455.

Thomas, D. D. S. (1978). Cytochalasin effects in plants and eukaryotic microbial systems. In Cytochalasins Biochemical and Cell Biological Aspects, pp. 257-275. Edited by S. W. Tanenbaum. Amsterdam: Elsevier/ North-Holland Biomedical Press.

Thomas, D. D. S. \& Mullins, J. T. (1969). Cellulase induction and wall extension in the water mould Achlya ambisexualis. Physiologia plantarum 22, 347353.

Thomas, D. D. S., Lutzac, M. \& Manavathu, E. (1974). Cytochalasin selectively inhibits synthesis of a secretory protein of cellulose in Achlya. Nature, London 249, 140-141.

TrincI, A. P. J. (1978). Wall and hyphal growth. Science Progress (Oxford) 65, 75-99.

TrincI, A. P. J. (1979). The duplication cycle and branching in fungi. In Fungal Walls and Hyphal Growth, pp. 319-358. Edited by J. H. Burnett \& A. P. J. Trinci. Cambridge: Cambridge University Press.

Turian, G. \& Michea-Hamzehpour, M. (1983). Parallel stimulation of mitochondrial $\mathrm{H}^{+}\left(\mathrm{Mg}^{2+}\right)$ ATPase and rate of germ tube outgrowth from conidia of Neurospora crassa. FEMS Microbiology Letters 20, 249-252.

Wessels, N. K., Spooner, B. S., Ash, J. F., Bradley, M. O., Luduena, M. A., Taylor, E. L., WrenN, J. T. \& YamadA, K. M. (1971). Microfilaments in cellular and developmental processes. Science 171, 135-143.

Yahara, I., Harada, F., Sekita, S., Yoshihira, K. \& NATORI, S. (1982). Correlation between effects of 24 different cytochalasins on cellular structures and cellular events and those on actin in vitro. Journal of Cell Biology 92, 69-78. 